\title{
Impact of Competency of Consulting Company on Business Performance: Focus on Franchise Companies*
}

\author{
Young-Re CHO ${ }^{1}$, Moon-Myoung KIM², Min-Gyo SEO ${ }^{3}$
}

Received: December 26, 2019 Revised: May 28, 2020 Accepted: June 05, 2020.

\begin{abstract}
Purpose - The purpose of this study was to structurally verify how the competency of consulting company affects the business performance of consulting client firms through consulting achievement and consulting utilization. It aims to provide information for successful consulting and suggest strategic measures to improve consulting performance. Research design, data, and methodology This study examines the structural relationship between competency of consulting company, consulting performance, and performance of consulting client firms. In this model, competency of consulting company consists of three sub-dimensions such as reputation, ability to perform business, and expertise. For these purposes, research model and hypotheses were developed. This survey was conduct ed for employees of companies that have experienced consulting in the past year. A total of 195 were used for this study. The data were analyzed using frequency analysis, confirmatory factor analysis, correlation analysis, and SEM with SPSS 18.0 and Amos 18.0 statistical program. Result - The results of this study are as follows. First, reputation, ability to perform business and expertise, which are sub-dimensions of consulting competence, was found to have positive effect on consulting achievements and also found to have a positive effect on utilization. Second, consulting performance was found to have positive effects on business performance of consulting client firms. It means that the management's willingness to utilize consulting results and the achievements of consulting performance have a positive effect on the company's management performance. Conclusions - Consulting firms need to perform customer-oriented consulting by accurately recognizing what management consulting is required by the client firms. The academic significance of this study was that the research was conducted through structural empirical analysis, not only from the relationship of competency of consulting company to consulting performance, but also to the relationship of business performance of client firms. In addition, the practical implication of this study is that clients can actively utilize the results of consulting to lead business performance.
\end{abstract}

Keywords : Management consulting, Competency of consulting company, Consulting performance, Business performance

JEL Classification Code : L10, L2, L8, M00

\section{1. 서론}

*This paper is a revised version of Young-Re Cho's master's thesis 1 First Author's Affiliation: A Master's Degree, Graduate School, Hansung University, Seoul, Korea, E-mail: yr1cho@hanmail.net 2 Second Author's Affiliation: Adjunct Professor, Hansung University, Seoul, Korea, E-mail: ansaud2@nate.com 3 Corresponding Author's Affiliation: Visiting Professor, Hansung University, Seoul, Korea, E-mail: gaeup@hanmail.net

(c) Copyright: The Author(s)

This is an Open Access article distributed under the terms of the Creative Commons Attribution Non-Commercial License (https://creativecommons.org/licenses/by-nc/4.0/) which permits unrestricted non-commercial use, distribution, and reproduction in any medium, provided the original work is properly cited.
현대 조직사회는 지식이 가장 중요한 자산으로 인식되며, 컨설팅산업은 이러한 지식을 기반으로 하는 대표적인 산업이다(Sarvary, 1999). 컨설팅 산업은 외부 컨설턴트로부터 현재 기업들이 당면한 다양한 문제점을 객관적이고 전문적으로 진단하여 해결책을 제시하고 실행하는 방안에 대한 요구가 증가되면서 성장하고 있다(AlborsGarrogps. Ramos, \& Mas-Machuca, 2010). 또한, 기업의 객관적 진단을 통해 기업의 경쟁력 높이기 위한 정부지원이 컨설팅 산업을 성장시키고 있으나, 정부지원사업에 참여하여 수익 활동을 하고 있는 컨설팅 회사 간 경쟁도 심화되고 있다. 그러나 국내 컨설팅 기업의 경우 규모가 아직 영세하고 글로벌 컨설팅 기업과의 경쟁에서 경쟁력을 확보하지 못하고 있는 실정이다.

통계청(2014) 자료에 따르면 국내 컨설팅기업의 82\%가 10 명 미만의 컨설턴트를 보유하고 있다. 이와 같이 국내 컨설팅 기업의 영세성, 
컨설팅 분야의 다양성 미흡, 전문인력부족 등으로 컨설팅 서비스의 품질이 미흡한 실정이며, 이로 인하여 컨설팅 수진기업들의 국내 컨설팅 기업에 대한 신뢰도가 낮게 나타나고 있다(Bae, 2012). 따라서 컨설팅기업이 경쟁력을 갖추고 글로벌 컨설팅 기업에 대응하기 위해 정부와 국내 컨설팅 산업에 종사하고 있는 컨설팅사와 컨설팅 산업에서 경쟁력을 높이기 위한 다양한 방안을 고민해보아야 할 중요한 시점이다(Kim, 2010).

산업의 성장과 개별기업 간의 성장의 갭에 다른 문제로 인해 발생되는 다양한 문제에 대한 컨설팅기업의 질적.양적 성과 측정 및 정책적 대안이 절실하나, 국내 컨설팅기업과 관련 연구는 그 성장 속도에 비해 매우 부족한 상황이대(Shin \& Yu, 2012).

컨설팅관련 선행연구를 살펴보면, 컨설팅 수행을 위한 핵심적인 요소 중 하나인 컨설턴트의 역량이 컨설팅 성과 등에 미치는 영향에 대하여는 다양한 선행연구(Choi, 2014; Shin, 2012)가 진행되었다(Yu, 2015). 컨설턴트의 역량이 컨설팅 서비스품질과 고객만족과의 관계(Lee, 2015: Jang, 2011), 컨설턴트의 역량이 서비스품질, 컨설팅 성과에 미치는 영향에 관한 연구(Park, 2015; Bae, 2013; Shin, 2012)와 같이 대부분 개인의 역량을 중심으로 연구되어 왔으며 컨설팅사의 역량 측면에서의 연구는 부족한 것이 현실이다. 또한, 컨설팅성과 역시 컨설팅사의 관점위주로 측정됨으로써 컨설팅을 받는 수진기업의 경영성과에 미치는 영향을 종합적으로 제시하지 못하고 있다(Bae \& Ahn, 2013).

이에 본 연구에서는 컨설팅 성과에 영향을 미치는 요인들 중에서, 특히 컨설팅사역량과 컨설팅성과 및 수진기업의 경영성과를 구조적으로 살펴보고자 한다. 이를 위해 컨설팅사의 역량을 명성, 수행능력, 전문성 요인으로 구분하였으며, 컨설팅사의 역량이 컨설팅성과를 통해 수진기업의 경영성과에 미치는 영향을 파악하고자 한다. 본 연구 결과를 통해 국내 컨설팅산업에서 개인 컨설턴트의 역량이 아닌, 기업의 경쟁력 향상을 위한 전략적 제안을 제시하고자 하며, 수진기업, 컨설팅사, 컨설턴트에게 성공적인 컨설팅의 수행을 위한 정보를 제공함으로써 수진기업 측면에서는 경영컨설팅을 통한 성과 향상과 컨설팅사 측면에서는 국내 컨설팅사의 역량강화를 통해 결과적으로 국내 컨설팅 산업의 성장에 기여하고자 한다.

\section{2. 이론적 고찰}

\section{1. 컨설팅사 역량}

역량(competency)은 높은 성과를 창출하는 사람으로부터 일관되게 나타나는 행동 특성으로 규정할 수 있다 (Lee. Seo \& Km, 2010). Kemp(1980)는 직무 수행에 있어 보다 뛰어난 결과를 창출한 개인의 특성을 역량으로 정의하고, 역량은 과업을 수행하는데 있어서 행동으로
표출될 수 있다(Klemp, 1980)고 하였으며, Pary(1996)는 역량이 훈련에 의해 향상될 수 있는 것으로 보고 기준에 의하여 측정될 수 있는 지식, 태도, 스킬의 집합으로 파악하였다. 컨설팅의 역량은 연구자에 따라 다양하게 구분되고 있으나 대부분 컨설턴트가 갖추어야 할 전문성, 컨설팅 업무와 관련한 컨설턴트의 역할 및 개인적인 가치관과 특성을 중심으로 하는 구체적인 능력과 역량이 파악되고 있으며, 컨설팅업무 및 기업성과와의 관련성에 대한 연구가 대부분이다(Lee, Hwang, \& Lee (2012).

Williams and Woodward(1994)는 컨설팅사에 요구되는 역량의 관점에서 전문분야의 정보나 조언을 제공하는 전문가 역량, 프로젝트 전반을 관리하고 감독하는 관리자 역량, 전문지식을 습득하여 스스로 해결하도록 도와주는 교육자 역량을 컨설턴트의 핵심적인 역량 특성으로 제시한 바 있다(Kim \& Seok, 2012). 이와 같이 컨설팅의 주요역할은 정보제공, 문제해결, 변화계획 수립과 관리, 전문인력 제공, 활동제안서 개발, 관계자와 스태프의 훈련 사업적인 접촉과 연결 시스템 개선, 카운슬링 제공, 전문적인 의견 제공 등이 있다(Shin \& Yu, 2012).

컨설팅을 수행하는 대부분의 컨설팅사들은 특정 주체별로 자시의 고유 프로그램 그리고 컨설팅의 기법과 그 해결 도구 등을 가지고 있으며, 이러한 방법을 통해 컨설팅의 기법을 축적해 컨설팅 업을 유지하는 경우가 많다(Cho, 2005). 또한, 유명 컨설팅사의 경우 이러한 체계적인 문제 해결 기법이나 방법론만을 연구하는 전문적인 인력들이 따로 있는 경우가 대부분이며, 이러한 기법이나 컨설팅 방법론 등을 컨설턴트에게 교육시켜 실제 기업 프로젝트에 투입 시키고 있다lang, 2011). 컨설팅사의 노하우는 이러한 문제해결 방법론에 집약되어 있다고 볼 수 있을 것이다(Km, 2013). 경영 컨설팅의 목표 달성을 위해서 수진 기업 측에서 눈여겨보는 부분 중에는 첫째, 참여 컨설턴트 자신의 객관적인 경력 및 우수한 학력의 소유자인가? 둘째, 컨설팅사가 과거 비슷한 회사의 컨설팅 업무를 수행 결과가 있나? 셋째, 컨설팅사의 종업원 수가 많고 회사의 규모가 큰가? 넷째, 컨설팅사는 이 시장에서 이름이 알려져 있나? 다섯째, 기존 고객리스트 및 정보를 제공했나? 이다. 물론 이러한 수행과정 절차가 실제로 명확히 구분되지 않는다 하여도 수행과정을 단계별로 구분 지어 정리하는 노력이 컨설팅을 효과적으로 수행하는 데에 중요하다 (Kolb \& Frohman, 1970).

컨설팅사 역량과 컨설팅업무 또는 기업성과와의 관련성에 대해서는 컨설턴트 역량을 경영컨설팅의 핵심적인 성공요인으로 제시하거나 성공적인 컨설팅과업의 수행능력 또는 컨설팅과업의 성공적인 수행에 따른 경영성과의 영향을 분석하는 연구를 중심으로 이루어져 왔다Bae \&Ahn, 2013).

컨설팅사의 역량은 명성, 경험, 대처능력, 평판, 영향력, 전문기술 및 자사만의 원리원칙의 보유와 이에 대한 공정성, 준수, 약속의 이행으로 나눌 수 있다(lang, Lee \& Song, 2011). 
Jang and Lee (1998), Simon and Kumar (2001), Phillips (2006) 등은 컨설팅의 역량이 컨설팅성공의 주요요인에 포함되어야 한다는 점을 강조하였으며, Walker(2004)는 고객과의 의사소통, 고객과의 협조와 개입, 컨설턴트의 기술적 지식 등의 컨설턴트의 역량은 컨설팅성과에 영향을 미치는 유의한 요인이라고 주장하였다 (Walker, 2004).

Kwak(2008)는 전문성과 관리역량이 성공적인 컨설팅프로젝트수행에 영향을 미치는 요인이라는 결과를 제시하였으며, $\operatorname{Km}(2008)$ 은 전문성 역량이 컨설팅을 의뢰한 수진기업의 경영성과에 영향을 미친다는 점을 주장하였다(leong, 2012).

또한, Zeira \& Avedisian(1989)은 컨설턴트 특성 및 조직의 환경적 특성과 컨설팅 의뢰기업의 특성이 경영컨설팅 성과를 결정하는 주요요인이며, 최고경영자의 헌신 및 조직구성원들의 변화수용에 대한 태도 등의 기업특성은 컨설턴트의 특성과 조화를 이루어야 한다는 점을 강조하였다. 즉, 컨설팅 의뢰 기업에 실질적으로 도움되는 적절한 방법론과 컨설팅기법의 채택에 의한 컨설팅은 조직구성원의 주인의식과 책임의식 및 즉각적인 실행에 필요한 기동력, 최고경영자와 실무자의 적극적인 참여 등에 의해 컨설팅성과가 향상된다고 할 수 있다(Shapiro \& Soske, 1993).

선행연구를 종합하면, 컨설팅사의 역량은 대부분 관리, 실행, 참여와 같은 수행능력, 전문지식과 컨설팅 기법을 포괄하는 전문성, 인지도, 실적 등 컨설팅사의 명성으로 요약할 수 있다.

따라서 본 연구에서는 컨설팅사의 역량을 명성, 수행능력, 전문성으로 구분하고, 경영컨설팅 성과, 즉 컨설팅 프로젝트 완성도와 경영성과 활용도에 미치는 영향을 실증적으로 분석하고자 한다

\section{2. 컨설팅 성과}

컨설팅 프로젝트의 효과적인 수행을 위해서는 컨설턴트의 관리자적 역량이 중요하며, 컨설팅의 전문성에 관한 역량은 수진기업의 성과향상에 기여한다는 점을 시사하고 있다. Moon(2010)은 컨설팅 성공을 고객사의 성과향상으로 규정하고, 컨설턴트 개인이 부여해야 할 역량요인과 컨설팅프로젝트 관리차원의 역량이 모두 중시되어야 한다는 점을 지적하였다.

컨설턴트 특성과 함께 컨설팅 의뢰기업의 조직특성을 컨설팅성과에 영향을 미치는 요인으로 제시하고 컨설팅성과를 향상시키기 위하여 컨설턴트와 의뢰기업 조직특성 간의 상호작용을 중시할 것을 제안하고 있다(Byun, 2009). 창업기업을 대상으로 하여 컨설턴트와 컨설팅사의 특성으로서 인력규모, 수진기업의 업종이해도, 성취지향성 및 컨설팅방법론, 수진기업 특성으로서 컨설팅에 대한 신뢰도와 경영층 지원은 경영컨설팅성과에 유의한 정의 영향을 미친다는 점을 실증적으로 밝히고 있다(Byun, 2009).
컨설팅 성과는 주로 경영성과 기여도 지표와 컨설팅 프로젝트 완성도 지표로 구분하고, 경영성과 기여도 변수로는 기간준수, 예산범위 내 집행, 당초 설정한 컨설팅 목표 달성, 컨설팅 수행결과의 성공여부 등을 변수로 설정하였으며, 컨설팅 프로젝트 완성도 변수로는 의뢰고객의 컨설팅 만족도, 전통적 연구와 측정지표로서 재무적 성과요인인 매출액 증가와 수익성 개선을 제시하였다(Kwak, 2008).

Park(2015)은 컨설팅 성과 측면 변수를 컨설팅 프로젝트 완성도와 경영활동의 활용도로 구분하고, 컨설팅 완성도 변수로 기간준수, 예산 내 수행여부를 측정하였고, 경영성과 활용도 변수로 클라이언트 측이 제시한 문제해결의 정도, 목표달성 정도, 실제 활용정도, 의사결정 또는 업무수행능력 향상 정도, 유사 프로젝트 해결능력 보유정도, 전반적인 수행결과의 성공여부로 규정하였다(Park, 2015)

컨설턴트역량과 컨설팅성과 또는 기업성과와의 관련성에 대한 많은 연구에서는 컨설턴트역량이 경영컨설팅의 핵심적인 성공요인이라는 점을 강조하고 있으며, 경영컨설팅의 성공적인 수행은 대체로 기업의 경영성과에 긍정적인 영향을 미친다는 주장을 제시하고 있다(lang, 2011). 하지만 경영컨설팅의 구체적 성과에 관한 연구결과는 아직도 부족한 현실이며, 경영컨설팅의 성과와 관련한 거의 모든 연구는 주로 컨설팅사의 입장에서 성과를 올리기 위한 컨설팅으로 수익과 수진 기업의 관리에 관하여 집중되어오고 있다(Jang, 2009).

\section{3. 경영성과}

경영성과는 기업의 운영과 관련하여 성과란 과거 기업 활동의 효율성 및 효과성으로 정의할 수 있다(leong, 2012). 전통적으로 기업의 경영활동은 이익을 극대화하려는 영리활동이기 때문에 기업의 경영성과는 이익의 산출정도로 측정되었으나, 전통적인 재무적 관점은 고객과 경쟁적 측면을 경시하고 있다(Kwon, 2011). 때문에 재무적 성과와 병행하여 비재무적인 성과도 포함되어야 한다는 필요성이 제기되고 있다. 과거 기업의 성과평가는 주로 재무적인 성과의 평가에만 치우쳤으나, 기업환경이 복잡해지면서 더 이상 재무적인 성과의 측정만으로는 기업의 성과를 제대로 평가할 수 없게 되면서 점차 비재무적인 성과에 대한 측정과 평가에 관심을 돌리게 되었다(Han. Bae \& Lee, 2011: Kim, 2003). 기업이라는 조직이 경영될 때 어떠한 정보가 기업을 운영하는데 중요한 정보이고 핵심적인 정보인지를 알면 이 핵심 정보를 기반으로 효율적이며 신속한 조직 운영을 할 수 있다(Km, 2011). 여기에는 재무적 관점, 고객관점, 내부 프로세스 관점 그리고 학습과 성장관점이라는 4 가지 측면의 지표가 있는데 기업에서는 이 지표들을 파악하고, 그것에 따라 기업의 자원과 역량을 한 곳으로 집중시켜 나감으로써 기업의 전략 달성이 가능한 기업경영의 필수요소라고 할 수 있다(Kim, 2006). 
경영컨설팅관련 연구 대부분 컨설팅에 대한 성과를 측정하였으며, 컨설팅을 통한 기업의 경영성과를 포괄적으로 다른 연구는 미비하다. 관련 연구를 살펴보면, $\mathrm{Km}(2006)$ 은 경영 컨설팅과 경영 성과와의 관계 연구에서 성과평가 항목을 $\mathrm{BSC}$ 의 네 가지 관점으로 분류하여 제시하였다. 한편, $\mathrm{Km}$ (2011)은 컨설팅 성과를 고객만족, 내부개선 및 재무성과의 3 가지로 측정하였다. 이상에서 보았듯이 경영컨설팅과 경영성과와의 관계를 비교 분석하여 연구한 사례는 찾아보기가 힘들다. 그 이유는 경영성과의 객관적인 측정도 어려 울뿐만 아니라 특정 컨설팅과 경영성과를 직접 연관 지어 그 효과를 객관적으로 산출해 내기가 현실적으로 불가능하기 때문이다(Lee, 2013).

이와 관련하여 Kwak(2008)은 컨설팅 프로젝트의 성공적인 수행과 의뢰기업의 관점에서 파악된 경영컨설팅 성과를 구분하였으며, Kim (2008)은 컨설팅의 어떤 측면이 기업경쟁력을 높이는데 영향을 미치는지에 대한 연구와 함께 경영컨설팅 의뢰기업의 관점에서 컨설팅 성과를 평가하는 연구의 필요성을 제안하고 있다 (Kim 2008).

따라서 본 연구에서는 컨설팅 수진기업의 경영성과를 비재무적인 성과차원에서 구성원들의 내재된 직무수행 동기를 이끌어 내어 목표한 성과에 대한 달성 노력과 달성 정도로 정의하고 컨설팅 성과와의 관계를 분석하고자 한다.

\section{3. 연구설계}

\section{1. 연구모형}

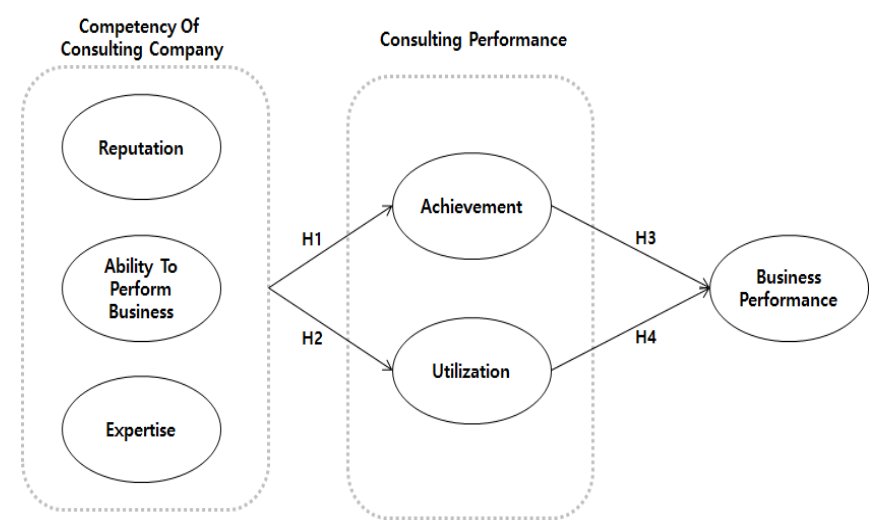

Figure 1: Hypothesized model

이에 본 연구는 이러한 목적을 달성하기 위하여 앞서 살펴본 선행연구를 바탕으로 컨설팅사 역량을 측정하는 변수를 컨설팅사의 명성, 컨설팅사의 수행 능력, 전문성 3 가지로 도출하였으며, Figure 1 과 같이 연구모형을 구성하였다.

\section{2. 연구가설}

\subsection{1 컨설팅사 역량이 컨설팅성과에 미치는 영향 간의 관계}

컨설팅업무 또는 기업성과와의 관련성에 대해서는 역량을 경영컨설팅의 핵심적인 성공요인으로 제시하거나 성공적인 컨설팅과업의 수행 또는 컨설팅과업의 성공적인 수행에 따른 경영성과의 영향을 분석하는 연구를 중심으로 이루어져 왔다(Bae, 2013). Jang(1996)은 성공적인 컨설팅 프로젝트의 수행을 위해서는 컨설턴트의 관리자적 역량이 중요하다고 하였으며, 컨설턴트의 전문성에 관한 역량은 의뢰기업의 성과향상에 기여한다는 점을 시사하고 있다Jang, 1996). Kwak(2008)은 전문성과 수행능력 등 관리적 역량이 컨설팅프로젝트의 성공적인 수행에 영향을 미치는 요인이라는 실증분석 결과를 제시하였으며, $\mathrm{Km}(2008)$ 은 전문성에 관한 역량이 컨설팅을 의뢰한 중소기업의 균형성과에 영향을 미친다는 점을 밝히고 있다(Km, 2008). 또한, 컨설팅 성공을 컨설팅 완성도와 고객사의 활용도로 규정하고, 컨설턴트 개인이 부여해야 할 역량요인과 컨설팅프로젝트 관리차원의 역량이 모두 중시되어야 한다는 점을 지적하였다(Moon et al, 2010).

이러한 선행연구의 결과를 근거로 하여 본 연구에서는 컨설팅사 역량과 컨설팅성과와 유의한 인과 관계가 있다고 보고 다음과 같은 연구가설을 설정하였다.

H1: 컨설팅사 역량은 컨설팅완성도에 정(+)의 영향을 미칠 것이다.

H1-1: 컨설팅사 명성은 컨설팅완성도에 정(+)의 영향을 미칠 것이다.

H1-2: 컨설팅사 수행능력은 컨설팅완성도에 정(+)의 영향을 미칠 것이다.

H1-3: 컨설팅사 전문성은 컨설팅완성도에 정(+)의 영향을 미칠 것이다.

H2: 컨설팅사 역량은 컨설팅 활용도에 정(+)의 영향을 미칠 것이다.

H2-1: 컨설팅사 명성은 컨설팅 활용도에 정(+)의 영향을 미칠 것이다.

H2-2: 컨설팅사 수행능력은 컨설팅 활용도에 정(+)의 영향을 미칠 것이다.

H2-3: 컨설팅사 전문성은 컨설팅 활용도에 정(+)의 영향을 미칠 것이다.

\subsection{2 컨설팅 성과가 경영성과에 미치는 영향 간의 관계}

경영컨설팅 성과는 컨설팅사의 관점에서 성공적인 컨설팅 과업의 수행으로 볼 수 있지만 컨설팅 의뢰기업의 입장에서는 컨설팅에 따른 업무프로세스의 개선이나 경영성과의 향상으로 규정할 수 있다KWak, 2008). 
이와 관련하여 Kwak(2008)은 컨설팅 프로젝트의 수행과 수진기업의 관점에서 파악된 경영컨설팅 성과를 구분하였으며, $\mathrm{Km}(2008)$ 은 컨설팅의 어떤 측면이 기업경쟁력을 높이는데 영향을 미치는지에 대한 연구와 함께 경영컨설팅 수진기업의 관점에서 컨설팅 성과를 평가하는 연구의 필요성을 제안하고 있다. Kim(2011)은 고객만족, 내부개선 및 재무성과를 컨설팅을 통한 경영성과로 보았다.

따라서 본 연구에서는 컨설팅성과와 경영성과 간에 유의한 관계가 있다고 보고 다음과 같은 연구 가설을 설정하였다.

H3: 컨설팅 완성도는 경영성과에 정(+)의 영향을 미칠 것이다.

H4: 컨설팅 활용도는 경영성과에 정(+)의 영향을 미칠 것이다.

\section{3. 변수의 조작적 정의}

\subsection{1. 컨설팅사 역량}

컨설팅사 역량은 '컨설팅 프로젝트 수행에 있어 컨설팅사가 보유하고 있는 기업적 특성으로 정의으며, 명성, 수행능력, 전문성으로 구분되었다. 컨설팅사의 명성은 평판, 경험, 인지도, 수행실적의 4 문항으로 측정하였으며, 수행능력은 명확한 목표설정, 의사소통, 프로젝트 관리, 과학적인 진단 및 분석, 사후관리의 5 문항, 전문성은 충분한 지식, 차별성, 자원의 활용, 설득능력, 유용한 정보의 5 문항이 likert 5 점 척도로 측정되었다.

\subsection{2. 컨설팅 성과}

컨설팅성과란 컨설팅 프로젝트의 수행결과로 수진기업이 요구한 컨설팅의 목적과 목표에 대한 달성 정도이다. 또한 컨설팅성과는 컨설팅 프로젝트 기간의 준수와 컨설팅 목적의 달성 여부를 확인할 수 있는 측정지표와 경영성과 기여도, 균형성과 지표 등과 같이 연구자들의 연구 목적과 대상에 따라 다양하게 구분될 수 있다(Km, 2015).

본 연구에서 컨설팅성과는 컨설팅 수진기업의 컨설팅 목적과 목표를 충족시키고 주어진 일정 내에 경영상의 주요 문제점과 이슈에 대한 과제의 도출과 해결방안을 제시하는 것으로서, 선행연구 결과를 바탕으로 컨설팅완성도 5 문항, 활용도 5 문항이 likert 5 점 척도로 측정되었다.

\subsection{3. 경영성과}

경영성과는 경영자가 구성원들의 내재된 직무수행 동기를 이끌어 내어 목표한 성과에 대한 달성 노력과 달성 정도이다(Schumann, 1994). 본 연구에서 경영성과는 선행연구 결과를 바탕으로 정성적인 성과를 나타내는 것으로서 의사결정향상, 조직효율성, 업무효율성,
경영문제해결, 경영혁신활동의 5 문항에 대하여 을 likert 5 점 척도로 측정되었다.

\section{4. 실증분석}

\section{1. 표본설계 및 분석방법}

본 연구에서는 연구목적에 맞게 컨설팅을 경험한 프랜차이즈 기업 임직원을 조사 대상으로 설정하였다.

본 연구는 변수들의 관계를 실증적으로 측정하기 위해 설문지법을 활용하였으며, 선행 연구를 바탕으로 본 연구에 적합한 설문문항을 구성하고, 일부 수정 및 내용을 추가하여 항목을 작성하였다.

재구성된 설문지를 통해 설문 항목의 적합성을 측정한 후, 일부 항목은 응답자의 이해도를 높이기 위해 수정 및 보완하여 본 조사에 활용하였다. 본 설문은 최근 1 년간 프랜차이즈 기업 중 컨설팅을 경험한 임직원을 대상으로 시행되었으며, 총 350 명을 대상으로 설문조사를 실시하였다. 이 중 210 부를 회수하였으나, 연구 결과의 정확도를 높이기 위해 불성실한 설문지를 제외하고 나머지 195 개의 설문지 표본으로 최종분석을 하였다. 수집된 자료는 가설관계의 검증을 위하여 SPSS 18.0 및 Amos 18.0 통계프로그램을 이용하여 분석되었다. 또한 연구내용내용에 따라 빈도분석, 신뢰도 분석, 요인분석, 상관관계분석과 구조방정식 분석 등의 분석이 실시되었다.

\section{2. 표본의 일반적 특성}

본 연구는 설문에 응답한 지 회수된 195 부의 응답자의 특성은 을 빈도분석을 통해 살펴보았다. 이를 정리하면 Table 1 과 같다. 먼저, 대부분의 응답자는 남성(74.9\%)이며, 30 대-40 대(73.8\%)가 가장 많았다. 컨설팅 유형은 FC 시스템 구축(37.9\%), 신브랜드 개발(18.5\%), 그리고 리브랜딩(17.4\%)의 순으로 나타났다. 사업유형은 식음료서비스(53.8\%)로 가장 많았으며, 다음으로 도소매(19.0\%)의 순으로 나타났다.

\section{3. 측정항목의 타당성 및 신뢰성 검증}

본 연구에서의 측정변수들이 연구개념을 지지하고, 측정모델이 구조가 타당한지를 검증하기 위하여 적합도를 검증하는 확인적 요인을 분석하였다. 분석 결과, $\chi^{2}$ 값은 $672.921(\mathrm{df}=335, \mathrm{p}=0.000)$ 며, $\chi^{2} / \mathrm{df}$ 값은 2.009, $\mathrm{GH}=0.871$ (AGH $=0.844), \mathrm{CH}=0.934, \mathrm{NH}=0.877, \mathrm{RMR}=0.031$ 로 대부분의 수치가 기준치를 충족하거나 유사한 값에 근접하고 있어 적합한 측정모델이라고 할 수 있다. 
또한, 구성개념별로 집중 타당성을 확인하기 위하여 평균 분산추출값(AVE) 및 합성신뢰도(CCR)가 산출되었다. 분석결과, $\mathrm{AVE}$ 는 0.5 이상, 합성신뢰도는 0.7 이상이 바람직한 데(Hair et al, 2006) 본 연구를 위한 구성개념별 AVE는 0.506 이상, 합성신뢰도는 0.813 이상으로 나타나 측정변수의 집중타당성이 확보되었다(see Appendix 1).

다음으로, 연구개념들의 판별타당성이 검증되었다. 판별타당성은 측정도구들이 서로 다른 요인을 측정하기 위해 사용되는 것을 검증하기 위한 것으로, 판별타당성의 검증은 주로 분산추출검증(vaniance extracted test)을 통해 확인하는 것이 일반적이다(Hatcher, 1994). 분산 추출검증은 각 요인의 분산 추출값(AVE)이 각 요인간의 상관관계 값의 제곱보다 클 경우 확보된다(Hatcher, 1994). 분석결과, 분산추출갑(AVE)의 최소값은 0.506 로 상관계수의 제곱 값의 최대치인 0.489 보다 크게 나타나 본 연구에서 사용된 측정항목들은 판별타당성이 확보되었다(see Appendix 2).

또한, 구성개념별로 집중 타당성을 확인하기 위하여 평균 분산추출값(AVE) 및 합성신뢰도(CCR)가 산출되었다. 분석결과, $\mathrm{AVE}$ 는 0.5 이상, 합성신뢰도는 0.7 이상이 바람직한 데(Hair et al, 2006) 본 연구를 위한 구성개념별 AVE는 0.506 이상, 합성신뢰도는 0.813 이상으로 나타나 측정변수의 집중타당성이 확보되었다(Appendix 1 Refer).

Table 1 : Demographic Profiles

\begin{tabular}{|c|c|c|c|}
\hline \multicolumn{2}{|c|}{ Category } & Frequency (n) & $\%$ \\
\hline \multirow{2}{*}{ Gender } & Male & 146 & $74.9 \%$ \\
\hline & Female & 49 & $25.1 \%$ \\
\hline \multirow{4}{*}{ Age } & $20 \mathrm{~s}$ & 31 & $15.9 \%$ \\
\hline & $30 \mathrm{~s}$ & 96 & $49.2 \%$ \\
\hline & $40 \mathrm{~s}$ & 48 & $24.6 \%$ \\
\hline & Over 50 & 20 & $10.3 \%$ \\
\hline \multirow{8}{*}{$\begin{array}{l}\text { Type of } \\
\text { Consulting }\end{array}$} & $\begin{array}{l}\text { FC system } \\
\text { construction }\end{array}$ & 74 & $37.9 \%$ \\
\hline & Re-branding & 34 & $17.4 \%$ \\
\hline & $\begin{array}{l}\text { New brand } \\
\text { development }\end{array}$ & 36 & $18.5 \%$ \\
\hline & Sales forecast & 15 & $7.7 \%$ \\
\hline & Overseas expansion & 1 & $0.5 \%$ \\
\hline & Education Consulting & 2 & $1.0 \%$ \\
\hline & $\begin{array}{l}\text { Key Performance } \\
\text { Indicators }\end{array}$ & 28 & $14.4 \%$ \\
\hline & Other & 5 & $2.6 \%$ \\
\hline \multirow{5}{*}{$\begin{array}{l}\text { Type of } \\
\text { business }\end{array}$} & Foodservice & 105 & $53.8 \%$ \\
\hline & Wholesale and retail & 37 & $19.0 \%$ \\
\hline & Service & 34 & $17.4 \%$ \\
\hline & $\begin{array}{l}\text { Manufacturing } \\
\text { business }\end{array}$ & 5 & $2.6 \%$ \\
\hline & Other & 14 & $7.2 \%$ \\
\hline
\end{tabular}

본 연구는 설문지 회수된 195 부의 응답자의 특성을 빈도분석을 통해 살펴보았다. 이를 정리하면 Table 1 과 같다.

\section{4..4. 연구가설의 검정}

\subsection{1 연구가설의 검증 결과}

이론 모형에 대한 적합도 분석 결과, $\chi^{2}$ 에 대한 $\mathrm{p}$ 값은 0.000 으로 통계적으로 유의하게 나타났으며 적합도 지수는 $\mathrm{CH}=0.921, \mathrm{GH}=0.859$, $\mathrm{AGH}=0.831, \mathrm{NH}=0.864, \mathrm{RMR}=0.046$ 로 구성개념들 간의 인과관계를 설명할 수 있는 것으로 나타났다.

연구가설을 검증한 분석 결과는 다음과 같다. 먼저, 컨설팅사의 역량이 컨설팅 완성도에 미치는 영향에 대한 가설검증 결과, 컨설팅사 역량 중 명성(경로계수 $=0.350, C R=4.728, p<0.001$ ), 수행능력(경로계수= $0243, C R=3.570, p<0.001$ ), 전문성(경로계수= 0259, $C R=3.480, p<0.001$ ) 모두 컨설팅 완성도에 유의한 정(+)의 영향을 미치는 것으로 나타나 $\mathrm{H} 1$ 은 모두 채택되었다.

컨설팅사 역량이 컨설팅 활용도에 미치는 영향에 대한 가설검증 결과, 컨설팅사 역량 중 명성(경로계수 $=0213, \quad \mathrm{CR}=2.882, \mathrm{p}<0.01$ ), 수행능력(경로계수 $=0389, C R=5.106, p<0.001)$, 전문성(경로계수 $=0249$, $\mathrm{CR}=2.946 \mathrm{p}<0.01)$ 모두 컨설팅 활용도에 유의한 정(+)의 영향을 미치는 것으로 나타나, $\mathrm{H} 2$ 도 모두 채택되었다.

다음으로, 컨설팅 성광 중 컨설팅 완성도가 경영성과에 미치는 영향에 대한 가설검증 결과, 유의한 정(+)의 영향을 미치는 것으로 나타나(경로계수 $=0289, \mathrm{CR}=5358 \mathrm{p}<0.001) \mathrm{H}$ 은 채택되었다. 컨설팅 활용도도 경영성과에 미치는 유의한 정(+)의 영향을 미치는 것으로 나타나경로계수 $=0.620, \quad C R=9349, \quad p<0.001) \quad H 4 \quad$ 역시 채택되었다(Appendix 3 Refer).

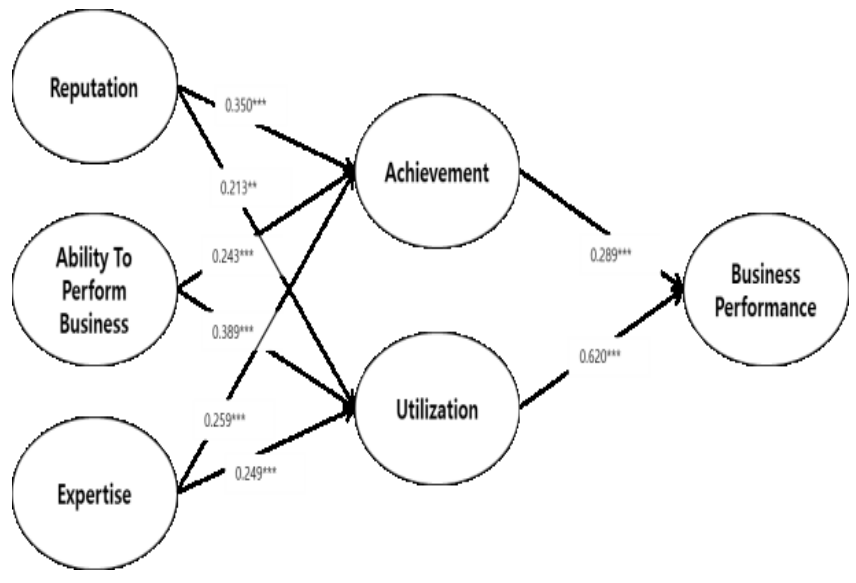

Figure 2: Estimates of the Structural Model 


\section{5. 결론}

\section{1. 연구결과의 요약 및 시사점}

본 연구에서는 컨설팅 성과에 영향을 미치는 요인 중 컨설팅사에 소속된 컨설턴트의 역량, 컨설팅사의 특성이 수진 기업의 컨설팅 완성도와 컨설팅 활용도를 통해 경영 성과에 어떠한 영향을 미치는지에 대하여 구조적으로 검증하였다.

본 연구에서 컨설팅사 역량과 컨설팅 프로세스의 완성도, 활용도 및 경영성과 간의 영향 관계를 파악한 결과, 컨설팅사 명성, 수행능력 및 전문성은 컨설팅 완성도에 긍정적인 영향 관계가 있는 것으로 나타났다. 또한, 컨설팅사 역량이 컨설팅 활용도에 미치는 영향에 대한 검증 결과, 컨설팅사의 명성, 수행능력, 전문성이 컨설팅 활용도에도 정(+)의 영향을 미치는 것으로 나타났다. 이는 Kwak(2008)과 Kim(2008)의 연구와 동일한 결과로 컨설팅사의 수행능력은 컨설팅 활용도에 높은 영향을 미치는 것으로 확인되어 명확한 목표와 범위설정, 목표달성을 위한 의사소통, 통제능력, 수진기업 임직원과의 조정, 수행과정을 명확하게 규정하고 관리 및 진단과 분석, 적절한 대안제시, 사후관리를 통한 컨설팅 노력이 완성도 있는 컨설팅 결과를 만들어낸다고 할 수 있다. 또한 컨설팅사가 컨설팅 완성도나 활용도, 경영자의 의지가 높은 컨설팅 수행 기업을 선택하여 컨설팅사가 컨설팅을 한다면 컨설팅 완성도는 뛰어날 수밖에 없다. 한편, 컨설팅사의 명성이 컨설팅 성과에 긍정적인 영향을 미치는 것으로 나타나, 컨설팅사의 명성이나 평판의 우수성을 지속 만들어 가는 컨설팅사의 매니지먼트도 중요하다고 할 수 있다. 또한, 컨설팅 결과물을 만들기 위해 컨설턴트나, 연구원의 프로젝트를 수행하는데 있어 자료 분석 결과를 적용하는 교육자적 역할을 원활하게 수행하여 컨설팅 목표치보다 그 이상의 결과물을 달성하여 컨설팅 수행기업으로부터 다시 수주를 받는 것이 컨설팅사의 명성을 확보하는 것이다.

본 연구에서 전문성은 충분한 지식, 새로운 지식과 독창적인 생각을 보유하고, 컨설팅 내용을 설득력 있게 전달 및 체계적으로 분석하여 서비스를 제공하는 것으로 평가하였다. 국내 소규모 컨설팅사의 전문성은 1 차적으로 상담 시 컨설팅사의 CEO 의 학력, 전문영역에서 명성 있는 근무 경력을 통한 커리어패스 보유, 대외 인지도 등에 따라 평가되어 해당 프로젝트 수행 수주에 절대적인 영향을 미친다고 볼 수 있다.

마지막으로 컨설팅성과 역시 경영성과에 긍정적인 영향을 미치는 것으로 나타났다. 이는 Yoon(2008)의 연구와 동일한 결과로 경영자의 컨설팅 산출물에 대한 활용 의지가 높고, 컨설팅 결과물이 완성도가 높을 경우에 기업의 경영성과에 긍정적인 영향을 미친다는 것을
의미한다. 컨설팅 결과물을 경영자의 의사결정 및 경영자문에 활용 계획에 반영하고자 하는 의지 역시 경영성과에 매우 중요한 요인이 될 수 있다.

본 연구의 학문적 의의는 컨설팅사의 역량이 컨설팅성과에 미치는 영향관계에서 그치지 않고 수진기업의 경영성과에 미치는 영향 관계까지 구조적인 실증분석을 통한 연구를 진행하였다는 것이다.

본 연구의 실무적 시사점은 다음과 같다.

수진기업의 컨설팅을 통한 성과 제고를 위한 컨설팅사의 특성과 컨설턴트의 역량 등 컨설팅을 받는 수진기업 입장에서 외적인 요인 뿐 아니라 수진기업이 컨설팅 과정에서 적극적인 활용을 할 때 컨설팅의 성공과 더 나아가 경영성과로 이어질 수 있다는 새로운 시각과 다양한 필요요건을 제시하였다는 점에서 실무적 의의가 있다고 할 수 있다.

또한, 컨설팅사의 수행 능력에 따라 컨설팅 수진기업의 컨설팅 활용도가 달라 질 수 있다. 즉, 컨설팅사가 노하우를 직접 실행하고 컨설팅 수진 기업이 즉시 배울 수 있고 적용할 수 있는 실무중심의 Action \& Leaming 컨설팅 방식으로 컨설팅을 진행할 경우 컨설팅 수진기업은 즉시 컨설팅사로부터 노하우를 배우고 기업에 적용을 바로 할 수 있게 되므로 단순이 보고서만 제공하는 방식이 아닌, 실무에 적용할 수 있는 컨설팅 방식인지 세밀하게 살펴보아야 할 것이다.

\section{2. 연구의 한계 및 향후 연구 과제}

본 연구는 프랜차이즈 기업 경영 시스템을 운영함에 있어 컨설팅사의 분야에 따라 컨설팅 완성도와 활용도에 따라 경영 성과에 미치는 영향을 비교 분석하지 못함이 한계점으로 대두되었다. 경영 컨설팅에 대한 기업의 형태에 따라 영향이 다르게 나타날 수 있다. 이는 컨설팅 기업의 규모, 인적 구성, 전문성 등의 차이에 따른 성과 비교분석이 필요할 것으로 판단된다.

한편, 사후관리를 통해 수진기업이 컨설팅 결과물을 적극 활용하게 함으로 수진 기업의 경영 성과를 높이고, 해당 컨설팅사와의 관계를 장기적으로 유지하면서 재계약 창출이나 컨설팅 시장 내에서 입소문으로 효과를 얻으며 컨설팅사는 이로 인해 마케팅 비용이 절감되는 효과도 얻을 수 있다.

즉, 컨설팅 프로세스에서 사후 관리는 컨설팅 활용도 및 경영성과에 매우 중요한 요인이나, 대다수의 컨설팅사의 서비스 제공이 전문 인력의 문제점과 수진 기업의 영세성으로 인해 계약이 종료되면 수진기업에 추가적인 서비스 제공을 하지 못하는 게 현실이다.

따라서, 컨설팅 성과에 따른 사후관리 Needs 및 사후관리의 영향요인에 대한 복합적인 연구가 필요할 것으로 판단된다. 


\section{References}

Albors-Garrogps. K. Ramos. J.C. \& Mas-Machuca. M. (2010). Actional intelligence. A critical competence for innovation performance. A research multi-case analysis. International Journal Technology and Planning., 6(3). ), 210-225.

Bae, Y. S. \& Young, J. A. (2013). A study on the competency of consultants influencing management consulting performance: moderating effect of consulting firm and firm characteristics. Korean Journal of Service Management, 14(3), 25-40.

Hair, J. F., Black, W. C., Babin, B. J., Anderson, R. E., \& Tatham, R. L. (2006). Multivariate data. New York: Macmillan College Pub.

Han, S. H. \& Bae, G. C., \& Lee, J. H. (2011) The effect of franchisor's pre-open support services on franchisee's relationship quality and performance in foodservice franchise system, Journal of Franchise Management, 2, 152-172.

Jang, Y. S. (2011). A study on the quality and customer satisfaction of SME consulting services. Quality Management Research. 39(1). 24-33.

Jang, Y. \& Lee, J. (1998). Factors influencing the success of management consulting projects. International of Project Management., 16(2),. 67-72.

Jang, D. I. \& Lee, K. H. \& Song, S, H. (2011). A study on the effect of consultant's competency on consulting service quality and customer satisfaction: Focusing on the moderating effect of support. Customer Satisfaction Management Research, 13(3), 39-64.

Jo, Y. D. (2005). Business consulting service. Seoul: Namdu books. Klemp, G. O. (1980). The assessment of occupational competence. Washington, DC: National Institute of Education.

Kim, J. K. \& Seok, C. (2012). The impact of management consulting service quality on corporate performance and consultant change. Tax Accounting Research, 32, 133-159.

Kim, M. \& Jang, S. (2015). A study on the moderating effect of transformational leadership in the relationship between management consultant capabilities and management performance. Management Consulting Research, 15(1), 195210.

Kolb. D. A. \& Frohman, A. L. (1970). An development approach to consulting". Sloan Management Review. Fall. 51-56.

Kwak, H. J. (2008). A study on building a success model to improve consulting performance in the Korean consulting market: focusing on the SME management consulting market. Professional Management Research, 11(1), 1-23.

Lee, B. J., Jang, S. H. \& Lee, J. H. (2011). A study on the moderating effect of PM competency on the influence of consultant competency on consulting performance. Digital Convergence Research, 9(6), 255-266.

Lee, J. E., Seo, C. S., \& Kim, S. C. (2010). A study on consultant competency models: focusing on competency comparison of large and small business consultants using AHP technique. Journal of the Korean Operations Research Society, 253-274.

Lee, Y. W., Hwang, S. J., \& Lee, C. S. (2012). Analysis of the relationship between consultant competency and management consulting completion and control factors. Industrial Economic Research, 25(1), 315-337.

Park, C. R., Hwang, S, J., \& Lee, C. S. (2011). The mediating effect of the relationship between management consulting and corporate performance and consulting utilization. Industrial Economic Research, 24 (6), 3371-3388.

Parry, S. B. (1996). Just Wwhat ils a cCompetency?(And wWhy sShould yYou cCare?). Training, 35(6), 58-60.

Phillips Jack. (2006). How to build a successful consulting practice?. NY: McGraw-Hill.

Sarvary. M. (1999). Knowledge management and competition in the consulting industry. California Management Review, . 41(2), 95-107.

Shapiro, E. C., Eccles, R. G., \& Soske, T. L. (1993). Consulting: has the solution become part of the problem?. MIT Sloan Management Review, 34(4), 89-95.

Shin, D. J. \& Y, W. (2012). Impact of consultant capabilities on consulting service quality and consulting performance. Digital Convergence Research, 10(4), 63-78.

Simon, A \& Kumar, V. (2001). Clients views on capabilities which lead to management consulting success. Management Design,. 39(5), 362-372.

Walker James. (2004). Consulting outcomes research project. ND Small Business Development Center. University of North Dakota. p.6.

Williams, A. P. \& Woodward, S. (1994). Consultancy roles. In the competitive consultant. London: Palgrave Macmillan.

Zeira, Y. \& Avedisian, J. (1989). Organizational planned change: Assessing the chances for success. Organizational Dynamics, 17(4), 31-45. 


\section{Appendixes}

Appendix 1: Measurement items and validity assessment

\begin{tabular}{|c|c|c|c|c|c|c|}
\hline \multicolumn{2}{|c|}{ Constructs and Items } & Standardized Estimate & S.E. & C.R. & AVE & CCR \\
\hline \multirow{4}{*}{ Reputation } & 1 & 0.817 & & & \multirow{4}{*}{0.594} & \multirow{4}{*}{0.813} \\
\hline & 2 & 0.846 & 0.068 & $16.021^{* * *}$ & & \\
\hline & 3 & 0.786 & 0.063 & $14.808^{* * *}$ & & \\
\hline & 4 & 0.613 & 0.073 & $10.971^{* \star *}$ & & \\
\hline \multirow{5}{*}{$\begin{array}{l}\text { Ability To } \\
\text { Perform } \\
\text { Business }\end{array}$} & 1 & 0.775 & & & \multirow{5}{*}{0.577} & \multirow{5}{*}{0.870} \\
\hline & 2 & 0.761 & 0.073 & $13.597^{\star * \star}$ & & \\
\hline & 3 & 0.68 & 0.085 & $11.971^{* * *}$ & & \\
\hline & 4 & 0.785 & 0.082 & $14.063^{* * *}$ & & \\
\hline & 5 & 0.792 & 0.078 & $14.215^{\star * *}$ & & \\
\hline \multirow{5}{*}{ Expertise } & 1 & 0.683 & & & \multirow{5}{*}{0.506} & \multirow{5}{*}{0.816} \\
\hline & 2 & 0.679 & 0.1 & $10.397^{\star * *}$ & & \\
\hline & 3 & 0.731 & 0.101 & $11.069^{* * *}$ & & \\
\hline & 4 & 0.783 & 0.105 & $11.676^{\star * *}$ & & \\
\hline & 5 & 0.673 & 0.1 & $10.313^{* * *}$ & & \\
\hline \multirow{5}{*}{ Achievement } & 1 & 0.75 & & & \multirow{5}{*}{0.554} & \multirow{5}{*}{0.870} \\
\hline & 2 & 0.771 & 0.083 & $13.296^{\star * *}$ & & \\
\hline & 3 & 0.716 & 0.081 & $12.287^{\star \star \star}$ & & \\
\hline & 4 & 0.732 & 0.08 & $12.591^{* \star *}$ & & \\
\hline & 5 & 0.753 & 0.084 & $12.968^{\star * *}$ & & \\
\hline \multirow{5}{*}{ Utilization } & 1 & 0.684 & & & \multirow{5}{*}{0.681} & \multirow{5}{*}{0.910} \\
\hline & 2 & 0.818 & 0.082 & $13.214^{* * *}$ & & \\
\hline & 3 & 0.889 & 0.085 & $14.212^{* * *}$ & & \\
\hline & 4 & 0.899 & 0.092 & $14.342^{* * *}$ & & \\
\hline & 5 & 0.819 & 0.094 & $13.234^{* * *}$ & & \\
\hline \multirow{5}{*}{$\begin{array}{c}\text { Business } \\
\text { Performance }\end{array}$} & 1 & 0.826 & & & \multirow{5}{*}{0.605} & \multirow{5}{*}{0.873} \\
\hline & 2 & 0.72 & 0.06 & $13.88^{* * *}$ & & \\
\hline & 3 & 0.765 & 0.059 & $15.043^{\star * *}$ & & \\
\hline & 4 & 0.753 & 0.069 & $14.726^{\star * *}$ & & \\
\hline & 5 & 0.82 & 0.063 & $16.543^{\star * *}$ & & \\
\hline
\end{tabular}

